\title{
Mathematical simulation of separating work tool technological process
}

\author{
Sylwester Tabor ${ }^{1 *}$, Aleksandr Lezhenkin ${ }^{2}$, Serhii Halko ${ }^{2}$, Aleksandr Miroshnyk ${ }^{3}$, Stepan \\ Kovalyshyn ${ }^{4}$, Aleksandr Vershkov ${ }^{2}$ and Olena Hryhorenko ${ }^{2}$ \\ ${ }^{1}$ Faculty of Production and Energy Engineering, University of Agriculture in Krakow, Balicka 116B, \\ 30-149 Krakow, Poland \\ ${ }^{2}$ Dmitriy Motornyi Tavria State Agrotechnological University, 72310, Melitopol, Ukraine \\ ${ }^{3}$ Kharkiv Petro Vasylenko National Technical University of Agriculture, 61002, Kharkiv, Ukraine \\ ${ }^{4}$ Faculty of Mechanics and Power Engineering, Lviv National Agrarian University, 80381, Lviv, \\ Ukraine
}

\begin{abstract}
The article describes the technological process of separation of the heaped-off pile of wheat. A mathematical model in the form of regression equations was obtained based on a full-factor experiment. Using the methods of mathematical analysis, the regression equations were investigated for the highest and lowest values. The values of the factors were obtained, for which the response function has the highest values, then the response surfaces were constructed and analyzed.
\end{abstract}

\section{Introduction}

As it is commonly known from literature [1, 2], the most effective method of harvesting grain crops is their combing at the root with subsequent stationary re-processing. The most problematic link in this technology is the separation of combed heaps. To solve this problem various designs of separating devices have been proposed.

The way for the separation of a culmiferous heap merits consideration. The implementation of this method of separation has allowed us to develop a number of devices [3].

This separating body was mounted in a combine for harvesting grain crops [3]. The field studies [4] proved the effectiveness of the proposed design for the separation of a heaped-off pile of rice.

Works $[5,6]$ are devoted to the problem of separation, where the results of tests of vibration and gravity separators are discussed.

During the operation of the separating work tools, great attention is paid to the study of the fractional composition of a heap. So studies, which were carried out in harvesting winter wheat with a combine harvester with a double-drum combing device hung on it, showed that a heap of winter wheat contained $35-43 \%$ of free grain, $33-47 \%$ of dangling

\footnotetext{
* Corresponding author: sylwester.tabor@urk.edu.pl
} 
spikelets and $10-32 \%$ of coarse straw impurities. Based on studies [7] there is an average of $53.77 \%$ of free grain in battered heaps of winter wheat, $4.13 \%$ of dangling spikelets [8], $8.86 \%$ of chaff [9] and $33.2 \%$ of large straw impurities [10].

Therefore, the circuit solutions $[11,12]$ using cylindrical sieves with an outer working surface during the separation of the combed heap of cereal grains did not give the desired results in the course of experiments.

In our opinion, the most appropriate solution for the separation of combed heaps of grain crops is the work tool consisting of a segregator and a flat sieve, which is mounted in the cleaner of the combed heaps [13].

\section{Material and methods}

The program included: construction of a mathematical model of the technological process of free grain separation experimentally; statistical analysis of the model received as a result; study of the functions of the highest and lowest value response; building response surfaces.

To implement the program, an experimental laboratory unit was developed, the flow chart of which is shown in figure 1.

The technological process of the laboratory unit was as follows. An artificially prepared mixture comprising $60 \%$ of free grain, $5 \%$ of dangling spikelets, $35 \%$ of straw impurities (the method of preparation of the starting material is given in [4]) was loaded onto conveyor 2, from where it came to segregator 14, which, together with a sieve made an oscillatory motion. Due to the oscillations, the straw particles, moving, formed voids through which the grain was sieved down and collected in the lower part of the culmiferous layer. The segregated layer was fed to the sieve 15, where it was divided into two factions. Large straw impurities and dangling spikelets came off the sieve and along the inclined tray 17 fell into the sampler 19. The grain passed through the sieve holes and along the inclined tray 16 fell into the sampler 18 (Fig. 1). 


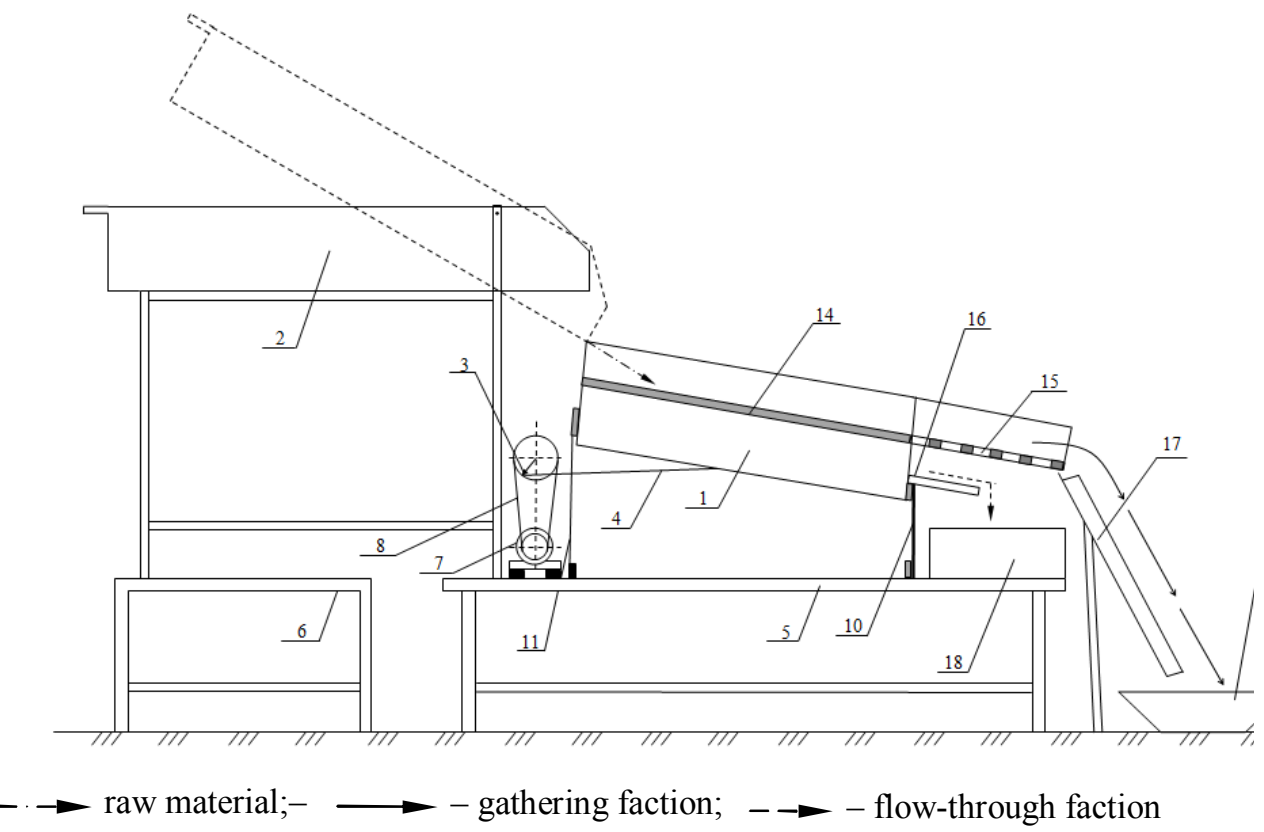

1 - shake mill; 2 - gravity conveyor; 3 - eccentric shaft; 4 - drive arm; 5 - frame; 6 . - slide; 7 - electric motor; 8 - multiple vee belt drive; 10,11 - plates; 14 - separator; 15 - sieve; 16 - duct for the flowthrough faction output; 17 - duct for the gathering faction output; 18,19 - sampler

Fig. 1. Technological scheme of the experimental laboratory unit

The mathematical theory of experiment planning was used to study the technological process of the work tool.

Analysis of various experimental plans allowed choosing the most rational plan for solving the tasks. Such a plan was the non-compositional, rotary three-level Box-Benkin plan.

Thus, a full-factor experiment was performed at three levels, for three factors, which was estimated by one response function. In general terms the mathematical model looks as follows:

$y_{1}=b_{0}+b_{1} x_{1}+b_{2} x_{2}+b_{3} x_{3}+b_{12} x_{1} x_{2}+b_{13} x_{1} x_{3}+b_{23} x_{2} x_{3}+b_{11} x_{1}^{2}+b_{22} x_{2}^{2}+b_{33} x_{3}^{2}$

where

$\mathrm{y}_{1}$ - shall mean the response function characterizing the change in a separation factor;

$\mathrm{x}_{1}$ - shall mean the specific feed of the source material to the work tool;

$\mathrm{x}_{2}$-shall mean the work tool oscillation frequency;

$\mathrm{x}_{3}$-shall mean the diameter of sieve holes;

$b_{0}, b_{1}, b_{2}, b_{3} \ldots$ - shall mean the regression coefficients of the first equation;

$c_{0}, c_{1}, c_{2}, c_{3} \ldots$ - shall mean the regression coefficients of the second equation.

Using the results of theoretical studies, as well as the analysis of literary sources $[14,15]$, the limits of the factors were identified and listed in Table 1 .

The significance of the regression coefficients was determined by Student's criterion, according to the recommendations of. The adequacy of the model was tested by the Fisher criterion.

In accordance with the plan of the experiment, the necessary kinematic and design parameters were set. The oscillation frequency was set using an autotransformer. All experiments were performed in triplicate. Using a table of random numbers, the experiments 
were randomized, which ensured the uniform introduction of the element of randomness of the influence of uncontrolled and uncontrollable factors on the response functions.

Table 1. Levels of factors variation

\begin{tabular}{|c|c|c|c|}
\hline \multirow{2}{*}{$\begin{array}{c}\text { The level and range of } \\
\text { factors variation }\end{array}$} & $\begin{array}{c}\text { specific feed of } \\
\text { material, } \mathrm{kg} \cdot \mathrm{s} \cdot \mathrm{m}^{2-1}\end{array}$ & $\begin{array}{c}\text { oscillation } \\
\text { frequency, } \mathrm{s}^{-1}\end{array}$ & $\begin{array}{c}\text { diameter of holes, } \\
\mathrm{mm}\end{array}$ \\
\cline { 2 - 4 } & $x_{1}$ & $x_{2}$ & $x_{3}$ \\
\hline Top level (+) & 3,3 & 55 & 35 \\
\hline Basic level (0) & 2,7 & 50 & 25 \\
\hline Lower level (-) & 2,1 & 45 & 15 \\
\hline Variation & 0,6 & 5 & 10 \\
\hline
\end{tabular}

\section{Results and discussion}

A general view of the mathematical model of this plan is represented by equation (1).

As a result of the calculations, the following values of the confidence intervals for the regression coefficients of the first equation were obtained:

$$
\Delta b_{0}= \pm 0,000572 ; \Delta b_{\mathrm{il}}= \pm 0,00043 ; \Delta b_{\mathrm{i}}= \pm 0,000215 ; \Delta b_{\mathrm{ii}}= \pm 0,00047
$$

When comparing the numerical values of the regression coefficients and their confidence intervals, it turned out that the coefficient $b_{1,2}=-0,00025$ is less than the confidence interval $\Delta b_{\mathrm{il}}= \pm 0,00043$. Consequently, this coefficient turned out to be insignificant and is not included in the model; besides, the coefficient $b_{13}=0$ is also not included in the model. All the remaining coefficients were greater than their confidence intervals, from which it follows that these regression coefficients are significant.

To assess the adequacy of the mathematical model obtained, the Fisher criterion was used. To do this, first the calculated value of the Fisher criterion was determined. The calculated value of the Fisher criterion is numerically equal to the ratio of the variance of adequacy to the variance of reproducibility and it is numerically equal to the first equation $S^{2}\{y\}=0,0004$. The variance of adequacy was also calculated, its numerical value was $S_{\alpha \delta}^{2}=0,0000066$ then using the obtained values of the variance of adequacy and variance of reproducibility, we determine the calculated value of the Fisher criterion for the first equation $F_{\mathrm{p}}=0,0165$. Comparison of the table value of the Fisher criterion and the calculated value showed that $F_{\mathrm{m}}>F_{\mathrm{p}}$ i.e. the model is adequate. Thus, as a result of the implementation of a second-order plan, a mathematical model (2) was obtained in the form of a second-degree polynomial, which adequately describes the process of separation of a combed heap.

$y_{1}=0,614-0,158 x_{1}-0,093 x_{2}+0,132 x_{3}-0,00175 x_{2} x_{3}+0,061 x_{1}^{2}-0,041 x_{2}^{2}-0,0665 x_{3}{ }^{2}$

The equation (2) characterizes the change in the separation coefficient depending on the parameters and modes of operation of the experimental working body. To analyze the equation (2), it is necessary to construct response surfaces.

First of all, we are interested in the highest values of the response function, i.e. the largest values of the separation coefficient. Thus, the task is reduced to determining the values of the factors (specific feed, oscillation frequency and hole diameter) at which the response function takes on the highest values. To solve this problem, it is necessary to investigate the regression equation, which is a function of several variables for the largest and smallest values. In the study of the function of several variables on the largest and smallest value in a closed space, the following algorithm was used:

a) partial derivatives of the first order were found, equated to zero, and the system $k$ of equations was solved $(k-$ shall mean the number of variables, and the system does not need 
not be linear);

b) after solving the system, critical points $M_{\mathrm{i}}\left(x_{1}, x_{2}, \ldots, x_{\mathrm{k}}\right)$ were obtained, where $i=\overline{1, m}, m$ - shall mean the highest degree of the system equations;

c) the values of the function at these points were determined, though an extremum study was not conducted;

d) the largest and smallest values of the function on each border of the closed space were found;

e) the largest and smallest values were selected from all the calculated ones.

According to the above methodology, we investigate the first regression equation:

$$
y_{1}=0,614-0,158 x_{1}-0,093 x_{2}+0,132 x_{3}-0,00175 x_{2} x_{3}+0,061 x_{1}^{2}-0,041 x_{2}^{2}-0,0665 x_{3}^{2}
$$

Take the partial derivatives of this function on the studied factors $x_{1}, x_{2}, x_{3}$.

$$
\left\{\begin{array}{l}
\frac{\partial y_{1}}{\partial x_{1}}=-0,158+2 \cdot 0,061 x_{1}, \\
\frac{\partial y_{1}}{\partial x_{2}}=-0,093-0,00175 x_{3}-2 \cdot 0,041 x_{2}, \\
\frac{\partial y_{1}}{\partial x_{3}}=0,132-0,00175 x_{2}-2 \cdot 0,00665 x_{3} .
\end{array} .\right.
$$

Equate equations (4) to zero and obtain an algebraic system of equations. Solve the system (5) relatively $x_{1}, x_{2}$ and $x_{3}$.

$$
\left\{\begin{array}{c}
-0,158+2 \cdot 0,061 x_{1}=0 \\
-0,093-0,00175 x_{3}-2 \cdot 0,041 x_{2}=0 \\
0,132-0,00175 x_{2}-2 \cdot 0,00665 x_{3}=0 .
\end{array}\right.
$$

From the first equation of system (5) we find $x_{1}$

$$
0,122 x_{1}=0,158 \Rightarrow x_{1}=1,295 \text {. }
$$

Then we shall determine $x_{2}$ and $x_{3}$

$$
\begin{gathered}
\left\{\begin{array}{c}
0,082 x_{2}+0,00175 x_{3}=-0,093 \\
0,00175 x_{2}+0,133 x_{3}=0,132
\end{array} \mid \begin{array}{l}
0,00175 \\
-0,082
\end{array}\right. \\
\left\{\begin{array}{c}
0,0001435 x_{2}+0,0000030625 x_{3}=-0,00016275 \\
-0,0001435 x_{2}-0,010906 x_{3}=-0,010824
\end{array}\right. \\
-0,0109029375 x_{3}=-0,01098675 ; x_{3}=1,008 \\
0,082 x_{2}+0,001763453=-0,093 ; 0,082 x_{2}=-0,094763453 ; x_{2}=-1,156
\end{gathered}
$$

Thus, as a result of solving the system of algebraic equations (5), we obtained the coordinates of the point $M\left(x_{1} ; x_{2} ; x_{3}\right)=M(1,295 ;-1,156 ; 1,008)$. However, this point is outside the study area and we discard it. Now we will explore the values of the function at the boundaries of a closed space.

1. Accept that factor $x_{1}=$ const and denote it by $c_{1}$. Substitute $c_{1}$ in the regression equation (3) instead of $x_{1}$ and receive the equation of the following form: 
$y_{1}=0,614-0,158 c_{1}-0,093 x_{2}+0,132 x_{3}-0,00175 x_{2} x_{3}+0,061 c_{1}{ }^{2}-0,041 x_{2}{ }^{2}-0,0665 x_{3}{ }^{2}$

Next, we shall conduct a study using a similar method. Take the partial derivatives of the response function for variable factors $x_{2}$ and $x_{3}$.

$$
\left\{\begin{array}{l}
\frac{\partial y_{1}}{\partial x_{2}}=-0,093+0,00175 x_{3}-0,082 x_{2}, \\
\frac{\partial y_{1}}{\partial x_{3}}=0,132-0,00175 x_{2}-2 \cdot 0,0665 x_{3} .
\end{array}\right.
$$

Equate each equation of system (7) to zero and as a result receive a system of two linear equations.

$$
\left\{\begin{array} { l } 
{ - 0 , 0 8 2 x _ { 2 } - 0 , 0 0 1 7 5 x _ { 3 } - 0 , 0 9 3 = 0 , } \\
{ - 0 , 0 0 1 7 5 x _ { 2 } - 0 , 1 3 3 x _ { 3 } + 0 , 1 3 2 = 0 . }
\end{array} \text { or } \left\{\begin{array}{l}
-0,082 x_{2}-0,0175 x_{3}=0,093, \\
0,00175 x_{2}+0,133 x_{3}=0,132 .
\end{array}\right.\right.
$$

Find from the system (8) indeterminates $x_{2}$ and $x_{3}: x_{2}=-1,156 ; \quad x_{3}=1,0008$.

Accept that $c_{1}$ may take the values: $-1 ;-0,5 ; 0 ; 0,5 ; 1$. The calculations of the values of the response function $y_{2}$ shall be carried out in each of the sections both inside these sections and at the nodal points. In cases the values $x_{2}$ or $x_{3}$ go beyond the zone of factor space, the value of the response function is not calculated

2. Accept that $x_{2}=c_{2}=$ const. Then the first regression equation of the model (2) shall be

$$
y_{1}=0,614-0,158 x_{1}-0,093 c_{2}+0,132 x_{3}-0,00175 c_{2} x_{3}+0,061 x_{1}^{2}-0,041 c_{2}^{2}-0,0665 x_{3}^{2}
$$

Take the partial derivatives of $y_{1}$ according to factors $x_{1}$ and $x_{3}$.

$$
\left\{\begin{array}{l}
\frac{\partial y_{1}}{\partial x_{1}}=-0,158+0,122 x_{1} \\
\frac{\partial y_{1}}{\partial x_{3}}=0,132-0,00175 c_{2}-0,133 x_{3}
\end{array}\right.
$$

Equate each equation of system (10) to zero.

$$
\left\{\begin{array} { l } 
{ - 0 , 1 5 8 + 0 , 1 2 2 x _ { 1 } = 0 , } \\
{ 0 , 1 3 2 - 0 , 0 0 1 7 5 c _ { 2 } - 0 , 1 3 3 x _ { 3 } = 0 . }
\end{array} \text { or } \left\{\begin{array}{l}
0,122 x_{1}=0,158 \\
0,00175 c_{2}+0,133 x_{3}=0,132 .
\end{array}\right.\right.
$$

From equations (11) we define $x_{1}$ and $x_{3}$.

$$
\left\{\begin{array}{l}
x_{1}=\frac{0,158}{0,122}=1,295, \\
x_{3}=\frac{0,132-0,0175 c_{2}}{0,133} .
\end{array}\right.
$$

The second equation of the system (12) includes a constant $c_{2}$, which can take the values: $-1 ;-0,05 ; 0 ; 0,5 ; 1$. These values are taken from the construction of the model and correspond to the points of the closed space. Substituting the values $c_{2}$ into equation (9), we 
define $x_{3}$ As a result of the calculations the following is received:

$$
\left.\left(x_{3}\right)\right|_{c_{2}=-1}=1,124 ;\left.\left(x_{3}\right)\right|_{c_{2}=-0,5}=1,058 ;\left.\left(x_{3}\right)\right|_{c_{2}=0}=0,992 ;\left.\left(x_{3}\right)\right|_{c_{2}=0,5}=0,927 ;\left.\left(x_{3}\right)\right|_{c_{2}=1}=0,861 .
$$

The obtained results are substituted into the regression equation (3) and the values of the response function $\mathrm{y}_{1}$ are determined.

3. Accept that $x_{3}=c_{3}=$ const and substitute $c_{3}$ into the regression equation (3), we obtain:

$$
\begin{aligned}
& y_{1}=0,614-0,158 x_{1}-0,093 x_{2}+0,132 c_{3}-0,00175 x_{2} c_{3}+0,061 x_{1}^{2}-0,041 x_{2}^{2}- \\
& 0,0665 c_{3}^{2} \\
& \left\{\begin{array}{c}
\frac{\partial y_{1}}{\partial x_{1}}=-0,158+0,122 x_{1} \\
\frac{\partial y_{1}}{\partial x_{2}}=-0,093-0,00175 c_{3}-0,082 x_{2}
\end{array}\right.
\end{aligned}
$$

Equate each equation of system (13) to zero.

$$
\left\{\begin{array}{l}
-0,158+0,122 x_{1}=0, \\
-0,093-0,00175 c_{3}-0,082 x_{2}=0 .
\end{array}\right.
$$

From the first equation of the system (14) $x_{1}=1,295$. From the second equation of the system (14) we determine $x_{2}$

$$
x_{2}=\frac{-0,093-0,0175 c_{3}}{0,082}
$$

Accept that $c_{3}$ changes within the limits from -1 to 1 , i.e. $c_{3}=-1, c_{3}=-0,5, c_{3}=0$, $c_{3}=0,5$ and $c_{3}=1$. Substitute in equation (15) the values that can take $c_{3}$, and as a result we receive the following values $x_{2}$, i.e.:

$$
\left.\left(x_{2}\right)\right|_{c_{3}=-1}=-1,113 ;\left.\left(x_{2}\right)\right|_{c_{3}=0,5}=-1,145 ;\left.\left(x_{2}\right)\right|_{c_{3}=-0,5}=-1,123 ;\left.\left(x_{2}\right)\right|_{c_{3}=1}=-1,155 ;\left.\left(x_{2}\right)\right|_{c_{3}=0}=-1,134
$$

As a result, we obtain the values $x_{1}, x_{2}, x_{3}$, which are substituted into the regression equation (3). After calculations, the values of the response function $\mathrm{y}_{1}$ are obtained at $x_{3}=$ const..

The results of calculations of the functions of the response $y_{1}$, showed that the greatest value of the response function $y_{1}=0,95225$ was taken when $x_{1}=-1, x_{2}=-1$ and $x_{3}=1$, therefore when constructing the surface of the response function, these values of the factors were taken.

At the first stage studies have been conducted of the response function at the maximum and minimum value, as a result, the values of factors at which the response function (equation 2) take the highest value were determined. Then one of the factors was recorded at the value at which the response function had the greatest value, and the other two factors were given different values from -1 to +1 . The construction of response surfaces was performed using Maple software.

As a result of the construction, three response surfaces were obtained. The response surface $\mathrm{x}_{1} \mathrm{x}_{2}$ of the separation coefficient is shown on fig.2. The greatest value of the separation coefficient 0.95 , is achieved when $x_{1}=-1, x_{2}=-1$ and $x_{3}=1$, when switching to natural values of factors, this means that the greatest value of the separation coefficient will be 
at a specif diameter o frequency, i.e. with th diameter $\mathrm{c}$ graphically

Fig. 3 s that the hic was reservi the diametr separation value of 0 .: sieve hole

Consid

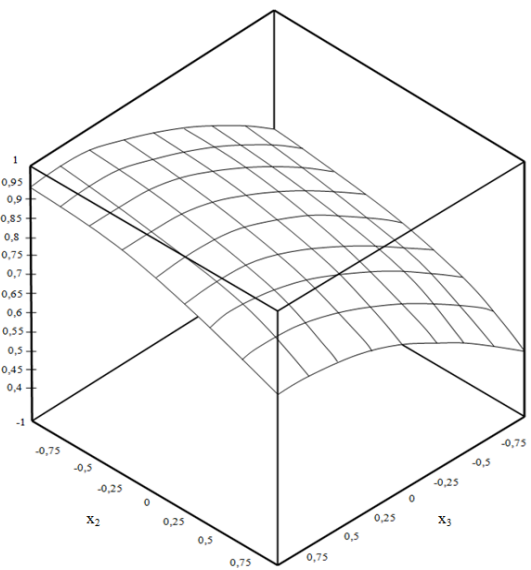

in frequency of $45 \mathrm{~s}^{-1}$ and a sieve hole ase in the specific feed and oscillation ts value at $x_{1}=1$ and $x_{2}=1$ reaches 0.45 , on frequency of $55 \mathrm{~s}^{-1}$ and a sieve hole ition factor. The response surface $x_{1} x_{2}$ $\mathrm{y}$ of the response function.

paration factor. The figure clearly shows rovided that $x_{1}=-1$ and $x_{3}=1$, while $x_{2}$ ase in the specific feed and a decrease in t. $x_{2}$ is regstered at $x_{2}=-1$ the value of the $r_{1}=1$ and $x_{3}=-1$ it reaches the smallest $\mathrm{m}^{2-1}$, oscillation frequency of $45 \mathrm{~s}^{-1}$ and a

coefficient. As Fig. 4 shows, the largest separation coemcient will de acneved provided tnat $x_{2}=-1$ and $x_{3}=1$, while $x_{1}=-1$ being reserved.

As the oscillation frequency increases and the diameter of the sieve holes decreases, the separation factor decreases, and at an oscillation frequency of $55 \mathrm{~s}^{-1}$ and a sieve hole diameter of $15 \mathrm{~mm}$ it is 0.5 . The response surface $x_{2} x_{3}$ clearly shows how the separation factor changes as the factors $x_{2}$ and $x_{3}$ change, i.e. the sieve oscillation frequency and the sieve hole diameter. Three response surfaces $x_{1} x_{3}, x_{1} x_{2}$ and $x_{2} x_{3}$ graphically characterize the process of changing the separation coefficient.

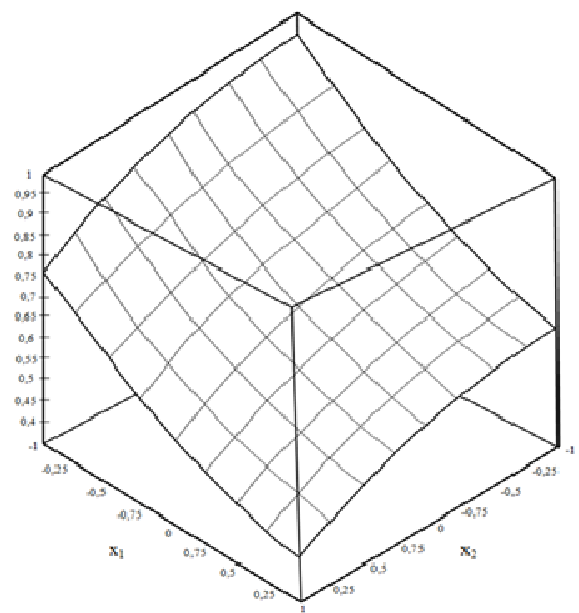

Fig. 2. Response surface $x_{1} x_{2}$ of the separation coefficient coefficient, factor $x_{3}$ is reserved for $x_{3}=1$

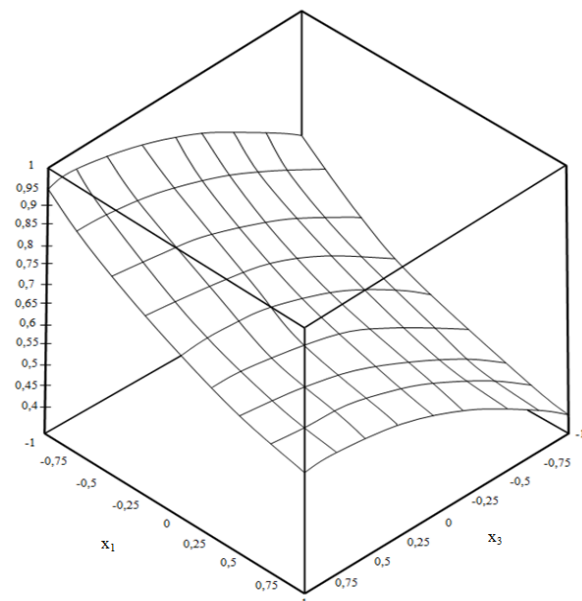

tactor $x_{2}$ is reserved for $x_{2}=-1$ 
Fig. 4. Response surface $x_{2} x_{3}$ of the separation coefficient, factor $x_{1}$ is reserved for $x_{1}=-1$

In all three cases, the greatest value of the separation coefficient is observed at a specific feed of combed heap to the sieve of $2.1 \mathrm{~kg} \cdot \mathrm{s} \cdot \mathrm{m}^{2-1}$, the sieve oscillation frequency of $45 \mathrm{~s}^{-1}$ and sieve hole diameter of $35 \mathrm{~mm}$, with such parameters and operating modes of experimental work tools the separation factor is 0.95 .

\section{Conclusions}

1. As a result of the implementation of the three-level Box-Benkin plan, we received the data which, by calculation, made it possible to determine the mathematical model ratios, which establish the dependence of the qualitative indicators of the separation of the work tool on the parameters and modes of its operation.

2. When conducting a statistical analysis of the significance of the regression ratios, it was established that the ratios $b_{12}=-0 ., 00025$ and $b_{13}=0$ were less than the confidence interval $\Delta b_{\mathrm{ij}}= \pm 0.00043$, which means that these factors are insignificant, all other ratios were greater than the confidence interval, which implies that these factors are significant. The evaluation of the adequacy of the model by the Fisher criterion showed that the model is adequate and this makes it possible to use it for further analysis.

3. The analysis of the regression model made it possible to substantiate the rational parameters of the work tool: diameter of openings is $35 \mathrm{~mm}$; specific feed of the combed heap $2.1 \mathrm{~kg} \cdot \mathrm{cm}^{2-1}$; oscillation frequency $45 \mathrm{~s}^{-1}$.

\section{References}

1. O. Lezhenkin, I. Lezhenkin, O. Vershkov, S. Kolomiiets, Trends and Innovations, 1, 8590, (2019).

2. O. Lezhenkin, I. Lezhenkin, O. Vershkov, S. Kolomiiets, Trends and Innovations, 1, 9198, (2019).

3. R. Myhan, E. Jachimczyk, Bios. Eng., 145, 93-107, (2016).

4. Gabitov, I. D. Badretdinov, S. G. Mudarisov, E. R. Khasanov, R. L. Lukmanov, R. R. Nasyrov, V. A. Pavlenko, J. Eng. App. Scien., 13, 6517-6526, (2018).

5. M. A. Sadek, Y. Chen, Canadian Bios. Eng. / Le Genie des biosystems au Canada, 55, 223- 231, (2013)

6. C. Bracacescu, I. Pirna, C. Sorica, S. Popescu, O. Stan, Eng. Rur. Develop., 11, 16-21, (2012). 
7. I. A. Lezhenkin, Pratsi Tavriiskoho derzhavnoho ahrotekhnolohichnoho universytetu, 13(2), 183-189, (2013).

8. I. A. Lezhenkin, Pratsi Tavriiskoho derzhavnoho ahrotekhnolohichnoho universytetu, 12(5), 149-154, (2012).

9. I. A. Lezhenkin, Visnyk Kharkivskoho natsionalnoho tekhnichnoho universytetu silskoho hospodarstva im. P. Vasylenka,132, 355-360, (2013).

10. I. A. Lezhenkin, Pratsi Tavriiskoho derzhavnoho ahrotekhnolohichnoho universytetu, 13(3), 57-62, (2013).

11. Separator of the scraped grain husk: pat. 92045 Ukraine. MPK B 07 B 1/22 (2006.01). \# a 201402219. Bul. 14. (2013).

12. I. A. Lezhenkin, Tekhniko-tekhnolohichni aspekty rozvytku ta vyprobuvannia novoi tekhniky i tekhnolohii dlia silskoho hospodarstva Ukrainy, 16 30, 437-440, (2012).

13. Treasurer of the scattered crowd: pat. 93931 Ukraine. MPK B 07 B 1/22 (2006.01). \# a 201403942. Bul. 20 (2014).

14. Z. Li. Y. Tang, H. Zhao, R. Mei, Y. Hui, Int. Agricul. Eng. J., 26 3, 103-111, (2017).

15.Z. Li. Y. Tang, Z. Liang, Nongye Gongcheng Xuebao/Transactions of the Chinese Society of Agricultural Engineering, 32 22, 70-76, (2016). 